\title{
A Tribute to Professor Jan Van Humbeeck: A Lifetime of Contributions to Understanding Martensite
}

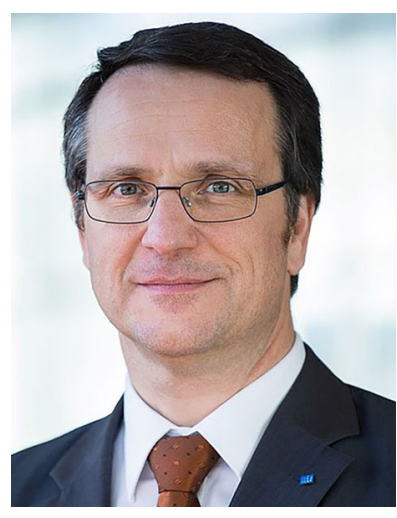

Hans J. Maier

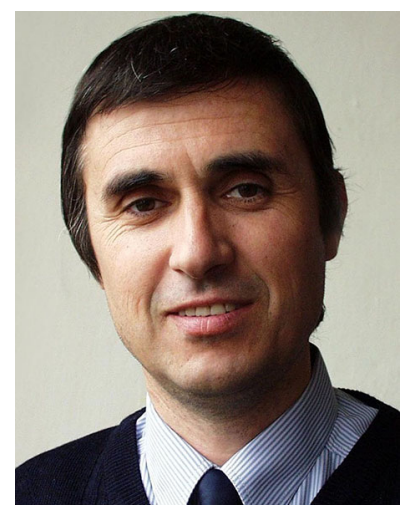

Petr Sittner

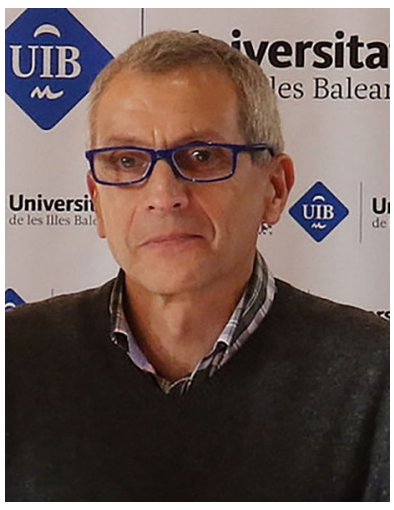

Sergey Kustov

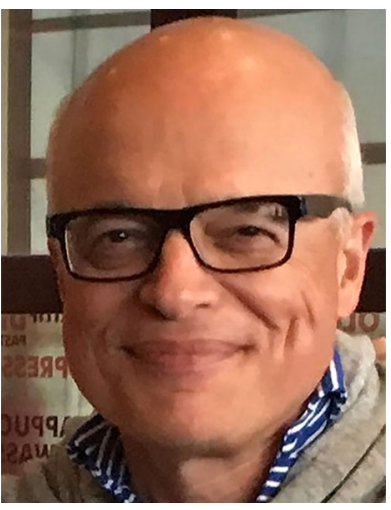

Huseyin Sehitoglu
This special issue of Shape Memory and Superelasticity is dedicated to Professor Jan Van Humbeeck on the occasion of his 65 th birthday, in recognition of his outstanding contributions to research in the area of shape memory materials.

Professor Van Humbeeck was born in Asse (Belgium) in 1952. During his studies of Applied Sciences at the Catholic University of Leuven he specialized in metallurgy. In 1983, he received his Ph.D. with distinction for a thesis on the damping properties of martensitic copperzinc-aluminum alloys. Early on, he published many influential papers on shape memory alloys, and thus received many invitations to spend research stays abroad. In fact, Jan has held many visiting positions at leading research institutions throughout the world. The center of his scientific activities was, however, always at the Catholic University of Leuven where he became full professor in 2003 in the Department for Metallurgy and Materials
Engineering. He invited many young scientists from all over the world to spend a few months or years working with him on shape memory alloys. These mostly young researchers later started their own shape memory research groups in their home countries or elsewhere, and today are part of a cadre of key scientists in the field. His publication record reflects scientific achievements and international collaborations at the highest level-near 300 co-authors from more than 20 countries.

Throughout his career, Jan amassed an impressive amount of highly cited papers in the most prestigious international journals, and the outstanding quality of his scientific work was recognized by various awards. Bridging the gap between basic sciences and real-world applications has always been one of his motivations, as reflected by his position as the co-founder of three spin-off companies. All of them exploit special material properties and processing techniques. He discussed biomedical 
applications of shape memory alloys in stents, in orthopedics, orthodontics, and biocompatibility issues in his papers. He drew attention to the need to understand the science behind shape memory alloys, to exploit them in critical actuation and damping applications. Being at the forefront of science and technology, he developed a unique stature in the field. Jan has always been very active in the SMA community, with involvement in all three key SMA conferences: ESOMAT, ICOMAT, and SMST.

When Jan began conducting research on shape memory materials, the field was still in its infancy. Since then, we have witnessed significant growth as demonstrated both by the increasing numbers of publications and patents issued per year. For many of the breakthroughs in this intricate scientific field, Jan has played a pivotal role. A case in point are his contributions to high-temperature shape memory materials well ahead of its time. In one of his early overview papers on the topic, Jan defined the minimum requirements for an industrial useful high-temperature shape memory alloy and also pointed out the major road blocks that need to be overcome with respect to mass application of these materials. Earlier in his career, Jan made groundbreaking contributions to understanding grain growth and martensite stabilization in Cu-based alloys. Some of these works highlighted the potential issues with $\mathrm{Cu}$-based alloys that were not well understood. On NiTi alloys, he wrote key papers on martensite detwinning, plastic flow, and nano-precipitation that are important topics of intense research today. Most recently, he explored the use of additive manufacturing techniques and specifically selective laser melting to produce shape memory alloys with very promising findings.

With the current special issue we try to both honor Jan's contributions to the field and also intend to provide a stimulus for further research with these fascinating materials. We are fortunate to know Professor Van Humbeeck and continue to benefit from his wisdom and advice. Undoubtedly, he will continue to be a strong advocate for the shape memory community and provide intellectual leadership. In addition to the March issue, the journal will continue to publish papers in celebration of Prof. Van Humbeeck in the June issue.

\section{Hans J. Maier}

Leibniz Universität

\section{Petr Sittner}

Academy of Sciences of the Czech Republic

\section{Sergey Kustov}

Universitat de les Illes Balears

\section{Huseyin Sehitoglu}

University of Illinois at Urbana-Champaign

Editor-in-Chief, Shape Memory and Superelasticity 